\title{
25 Research Soure \\ Studies on washability characteristics of low-volatile Indian coking coal by differential crushing
}

Sugali Sekhar Chandra ( $\nabla$ sugalichandra@gmail.com )

CSIR-Indian Institute of Chemical Technology

\section{Case study}

Keywords: Low Volatile Indian Coking coal, differential crushing, washability, Index of Washability, Near Gravity Material Index

Posted Date: September 10th, 2020

DOl: https://doi.org/10.21203/rs.3.rs-74261/v1

License: (c) (i) This work is licensed under a Creative Commons Attribution 4.0 International License.

Read Full License 


\section{Abstract}

The effect of differential crushing on liberation characteristics has been studied for a low volatile coking coal of Indian origin through washability studies. Two parameters, namely "Index of Washability" (IW) and "Near Gravity Material Index" (NGMI), are used to describe the ease of washability. The ROM Coal is crushed to four different top sizes namely, $75 \mathrm{~mm}, 25 \mathrm{~mm}, 13 \mathrm{~mm}$ and $6 \mathrm{~mm}$. On the basis of calculated IW it is observed that relative ease of washabiltiy increases with decrease in top size. From calculated IW values it may be said that this coal can be economically beneficiated using gravity process after crushing to $-6 \mathrm{~mm}$ size. From the calculated NGMI values, the critical specific gravities have been estimated and the values for crushing to $-75 \mathrm{~mm},-25 \mathrm{~mm},-13 \mathrm{~mm}$ and $-6 \mathrm{~mm}$ are $1.65,1.68,1.53$ and 1.58 respectively. These critical specific gravity values suggest the separation at this specific gravity range is most difficult task using gravity methods. From NGMI analysis, it may be said that the NGMI values for coals crushed to $-25 \mathrm{~mm} \&-6 \mathrm{~mm}$ are identical $(\approx 0.18)$ at $17 \%$ clean coal ash content. This suggests that with similar degree of difficulty, clean coal of $17 \%$ ash can be produced from these two different crushing sizes. In order to increase the yield for the clean coal of $17 \%$ ash, the decision on blending these two size coals may need to be taken.

\section{Introduction}

The top size of the coal to be washed usually has a bearing on the beneficiation process. Optimum crushing of the coal results in adequate liberation such that the combustibles can be easily separated by simple gravity separation methods [3]. It is well accepted practice to carry out the sink-float analysis of the coal to estimate its amenability towards gravity concentration methods. The data obtained from the sinkfloat analysis is used to plot the "washability curves" to extract valuable information regarding the clean coal that can be obtained from a given coal under ideal conditions [2]. From the sink-float analysis of a given coal, the amount of material floating at a particular specific gravity can be hypothetically considered as the recovery of two constituents, namely non-ash and ash forming materials. The coal which is easily washable will have complete liberation of non-ash material from ash material and the recovery of all nonash material present in the feed is possible without recovering ash material in the clean coal. On the contrary, the difficult-to-wash coal will have intimate locking of non-ash and ash materials and the ash content can not be reduced by physical beneficiation. Numerical indices such as 'washibility index' [4] and 'washibility number' [5] have been developed to quantify the amenability of given coal towards washing. The non-availability of any explicit mathematical expressions to estimate the ease of washing often posed a problem [1]. Keeping the above difficulty in view Govindarajan et al. [1] and Majumder et al. [2] developed mathematical expressions to calculate the 'Index of washbility (IW)' and 'Near gravity material index (NGMI)' respectively. The values of 'Index of washbility (IW)' vary from 0 to 100 for the 'difficult to wash' to 'easy to wash' [1]. The values of 'Near gravity material index (NGMI)' vary from 0 to 1 for the 'easy to wash' to 'difficult to wash' [2].

\subsection{Sample preparation and Characterization:}


The ROM coal (Feed ash 35.69\%) from Kuju mines in India has been crushed to below $75 \mathrm{~mm}, 25 \mathrm{~mm}$, $13 \mathrm{~mm}$ and $6 \mathrm{~mm}$ top size levels. The crushed coals were subjected to screening to ascertain the size distribution. The size wise ash analysis is shown in Table 1 for each top size level. The sink-float tests were carried out for each top size level using Zinc-chloride, Bromoform and Benzene solutions as heavy media at different specific gravities. The detailed washability analysis is shown in Fig.1.

\begin{tabular}{|c|c|c|c|c|c|c|c|c|c|c|c|}
\hline \multicolumn{3}{|c|}{$\begin{array}{l}\text { Crushed to below } \\
75 \mathrm{~mm} \text { size level }\end{array}$} & \multicolumn{3}{|c|}{$\begin{array}{l}\text { Crushed to below } \\
25 \mathrm{~mm} \text { size level }\end{array}$} & \multicolumn{3}{|c|}{$\begin{array}{l}\text { Crushed to below } \\
13 \mathrm{~mm} \text { size level }\end{array}$} & \multicolumn{3}{|c|}{$\begin{array}{l}\text { Crushed to below } \\
6 \mathrm{~mm} \text { size level }\end{array}$} \\
\hline $\begin{array}{l}\text { Particle } \\
\text { size } \\
(\mathrm{mm})\end{array}$ & $\begin{array}{l}W t \\
(\%)\end{array}$ & $\begin{array}{l}\text { Ash } \\
\text { (\%) }\end{array}$ & $\begin{array}{l}\text { Particle } \\
\text { size } \\
(\mathrm{mm})\end{array}$ & $\begin{array}{l}W \mathrm{Wt} \\
(\%)\end{array}$ & $\begin{array}{l}\text { Ash } \\
(\%)\end{array}$ & $\begin{array}{l}\text { Particle } \\
\text { size } \\
(\mathrm{mm})\end{array}$ & $\begin{array}{l}\mathrm{Wt} \\
(\%)\end{array}$ & $\begin{array}{l}\text { Ash } \\
(\%)\end{array}$ & $\begin{array}{l}\text { Particle } \\
\text { size } \\
(\mathrm{mm})\end{array}$ & $\begin{array}{l}\mathrm{Wt} \\
(\%)\end{array}$ & $\begin{array}{l}\text { Ash } \\
(\%)\end{array}$ \\
\hline$-75+50$ & 38.3 & 37.3 & $-25+13$ & 28.6 & 38.3 & $-13+6$ & 41.1 & 37.0 & $-6+3$ & 48.2 & 36.5 \\
\hline$-50+25$ & 30.7 & 36.8 & $-13+6$ & 20.8 & 36.9 & $-6+3$ & 17.7 & 36.0 & $-3+0.5$ & 31.5 & 36.5 \\
\hline$-25+13$ & 11.8 & 35.9 & $-6+3$ & 13.2 & 35.7 & $-3+0.5$ & 23.1 & 36.2 & -0.5 & 20.3 & 31.5 \\
\hline$-13+6$ & 5.9 & 34.1 & $-3+0.5$ & 21.0 & 34.5 & -0.5 & 18.1 & 32.4 & & & \\
\hline$-6+3$ & 3.2 & 35.4 & -0.5 & 16.4 & 31.9 & & & & & & \\
\hline$-3+0.5$ & 5.9 & 31.2 & & & & & & & & & \\
\hline-0.5 & 4.2 & 27.5 & & & & & & & & & \\
\hline
\end{tabular}

Table 1: Size wise ash analysis of Kuju coal at different crushing size levels.

\subsection{Estimation of Index of washability:}

For the calculation of Index of Washability (IW) of a given coal the recovery curves of non-ash and ash material have been drawn based on the assumption that recovery is a continuous function of cumulative fractional weight of the feed coal floated $(X)$ [1]. The typical recovery curves of normal and hypothetical coal crushed to below $75 \mathrm{~mm}$ size are shown in Fig.1. In this Figure, the curves ABC \& AEC represent the recovery curves of non-ash \& ash forming materials respectively.

From Fig. 2 Index of Washability (IW) of given coal was calculated as shown below:

IW $=$ Efficiency of Recovery of Non-ash Material $(E R N M) \times$ Differences in Recoveries

of Non ash and ash material (DRNM) $\times 100 / 3$

In the above equation, $\mathrm{ERNM}=$ area of $\mathrm{ABCA}$ / area of triangle $\mathrm{ADC}$

$\mathrm{DRNM}=$ area between the curves $\mathrm{ABC}$ and $\mathrm{AEC} /$ area of quadrangle $\mathrm{ADCF}$ 
From Equation (1), IW values have been estimated at each crushing size and reported in Table 2. From this Table, it is noted that the values of IW increases with the decrease in top size of the coal. This means that the relative ease of washability increases with crushing to lower sizes. The increase is not so significant for lowering the top size from $75 \mathrm{~mm}$ to $25 \mathrm{~mm}$. A significant improvement is observed when the sample is crushed to $-6 \mathrm{~mm}$ size. According to IW values shown in Table 2, it may be said that this coal can be economically beneficiated using gravity process after crushing to $-6 \mathrm{~mm}$ size.

\begin{tabular}{|lc|}
\hline Type of Coal & Calculated IW \\
\hline Crushed to $-75 \mathrm{~mm}$ & 30.9 \\
Crushed to $-25 \mathrm{~mm}$ & 31.9 \\
Crushed to $-13 \mathrm{~mm}$ & 34.0 \\
Crushed to $-6 \mathrm{~mm}$ & 41.4 \\
\hline
\end{tabular}

Table.2: The values of IW at different crushing sizes.

\subsection{Estimation of NGMI:}

Majumder et al. [2] has developed a method for calculating the near gravity material index (NGMI) from recovery curves of non-ash and ash forming materials.

In Fig. 3, curves $A B C$ and $A D C$ represent the recovery curves for non-ash and ash forming materials, respectively. The quantity of near gravity material index (NGMI) at a given specific gravity is defined as the difference in cumulative fractional weights floated at \pm 0.1 specific gravity of that specific gravity. In terms of recovery curves of non-ash and ash forming materials, the NGM distribution at a particular specific gravity may be geometrically represented by the area under the \pm 0.1 specific gravity of that specific gravity. This area will be different at different specific gravities of separation.

By the above definition, from Fig. 3, NGMI at points D \& B can be defined as:

$\mathrm{NGMI}=$ Area of $\mathrm{EFGH} /$ Area between curves $\mathrm{ABC}$ and $\mathrm{ADC}$

Using Equation (2), the NGMI values for different crushing sizes at different specific gravities have been calculated. The values of NGMI are plotted as a function of specific gravity of separation and shown in Fig. 4 Critical specific gravity is a specific gravity at which the value of NGMI is highest. From Fig. 4 the values of critical specific gravity are $1.65,1.68,1.53$ and 1.58 for coal crushed to $-75 \mathrm{~mm},-25 \mathrm{~mm},-13 \mathrm{~mm}$ and $-6 \mathrm{~mm}$, respectively. These values suggest that the separation at this specific gravity range is most difficult task using gravity methods.

From the washability data, the theoretical clean coal ash contents at those specific gravities are calculated and NGMI values are plotted as a function of clean coal ash contents as shown in Fig. 5 From this Figure, it may be observed that the NGMI values for coals crushed to $-25 \mathrm{~mm} \&-6 \mathrm{~mm}$ are identical $(\approx 0.18)$ at $17 \%$ clean coal ash content. Similarly, NGMI values for coals crushed to $-13 \mathrm{~mm} \&-6 \mathrm{~mm}$ are identical $\approx$ 
$0.23)$ at $19 \%$ and coals crushed to $-75 \mathrm{~mm} \&-6 \mathrm{~mm}$ are identical $(\approx 0.29)$ at $23 \%$ clean coal ash respectively.

This suggests that with similar degree of difficulty, clean coal of $17 \%, 19 \% \& 23 \%$ ash can be produced from two different crushing sizes. In order to increase the yield for the clean coal of $17 \%, 19 \% \& 23 \%$ ash the decision on blending of $-25 \mathrm{~mm} \&-6 \mathrm{~mm},-13 \mathrm{~mm} \&-6 \mathrm{~mm}$ and $-75 \mathrm{~mm} \&-6 \mathrm{~mm}$ size coals may need to be taken respectively.

\section{Conclusions}

This study reveals that combination of IW and NGMI could be used to evaluate the ease of beneficiation of coal using gravity methods. IW would determine the liberation size at which the ROM coal should be crushed. Critical specific gravity based on NGMI analysis would determine the operating difficulties. From calculated IW values, it may be said that this coal can be economically beneficiated using gravity process after crushing to $-6 \mathrm{~mm}$ size.

From NGMI analysis, it may be said that the NGMI values for coals crushed to $-25 \mathrm{~mm} \mathrm{\&}-6 \mathrm{~mm}$ are identical $(\approx 0.18)$ at $17 \%$ clean coal ash content. Similarly, NGMI values for coals crushed to $-13 \mathrm{~mm} \&$ $-6 \mathrm{~mm}$ are identical $(\approx 0.23)$ at $19 \%$ and coals crushed to $-75 \mathrm{~mm} \&-6 \mathrm{~mm}$ are identical $(\approx 0.29)$ at $23 \%$ clean coal ash respectively. This suggests that with similar degree of difficulty, clean coal of $17 \%, 19 \%$ \& $23 \%$ ash can be produced from two different crushing sizes. In order to increase the yield for the clean coal of $17 \%, 19 \%$ \& $23 \%$ ash the decision on blending of $-25 \mathrm{~mm} \&-6 \mathrm{~mm},-13 \mathrm{~mm} \&-6 \mathrm{~mm}$ and $-75 \mathrm{~mm}$ \& $-6 \mathrm{~mm}$ size coals may need to be taken respectively.

\section{References}

1. Govindarajan B, Rao TC (1994) Indexing the washability characteristics of coal. Int J Miner Process 42:285-293

2. Majumder AK, Barnwal JP (2004) Development of a new coal washability index. Miner Eng 17:93-96

3. Sarkar GG, Bose RN, Mitra SK, Lahiri A (1962) An index for the comparison and correlation of washability characteristics of coal, IVth Coal Preparation Congress, Harrogate, paper E 4

4. Vanangamudi M, Rao TC (1983) A convenient Index for the assessment of washbility characteristics of coal, Journal of Mines, Metals and Fuels, special number on coal preparation

5. Sarkar GG, Das HP, Ghose A (1977) Sedimentation patterns do they offer clues to coal quality, World Coal, $10-13$

\section{Figures}




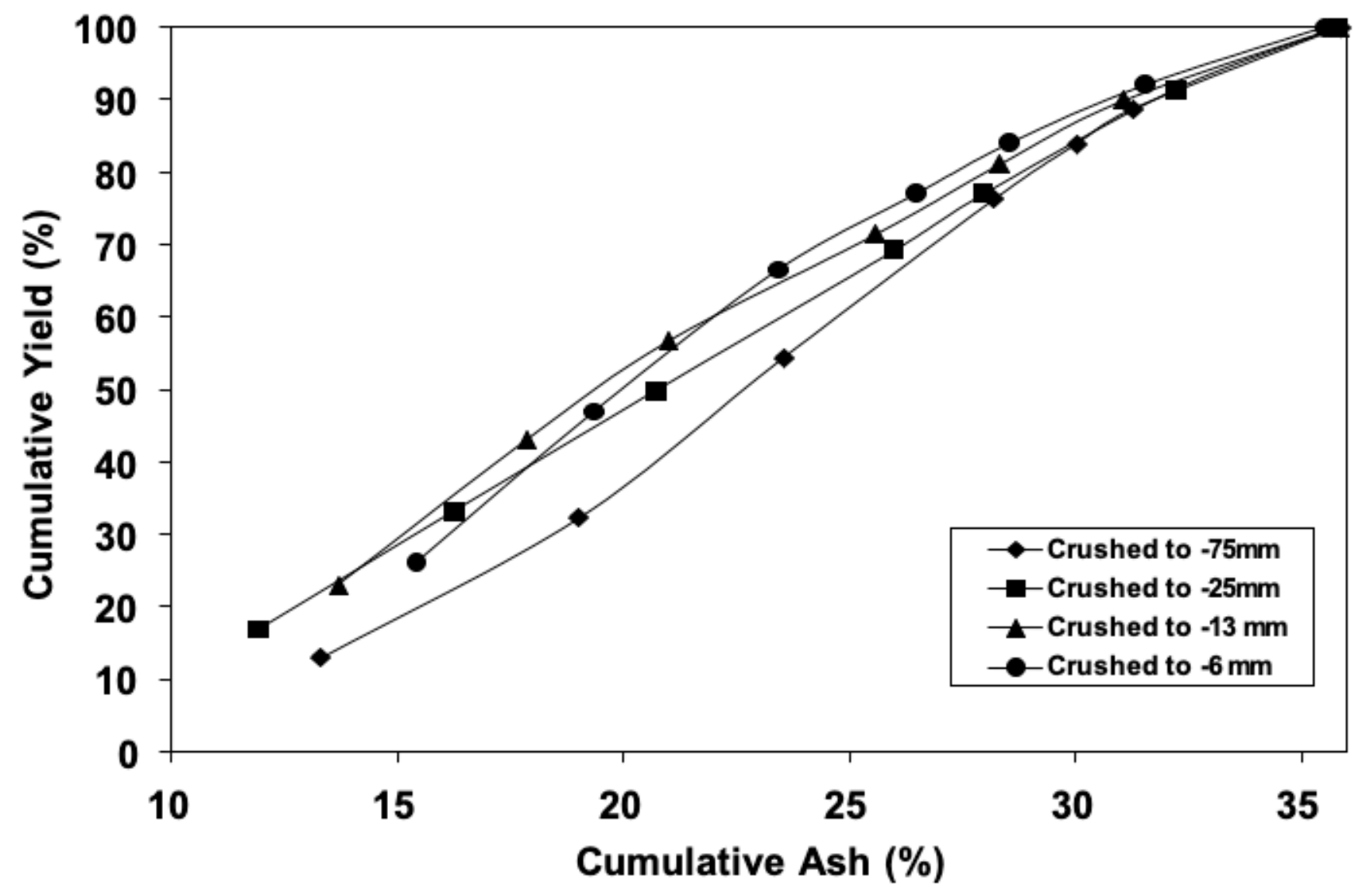

Figure 1

Washability curves for coal crushed to different top sizes 


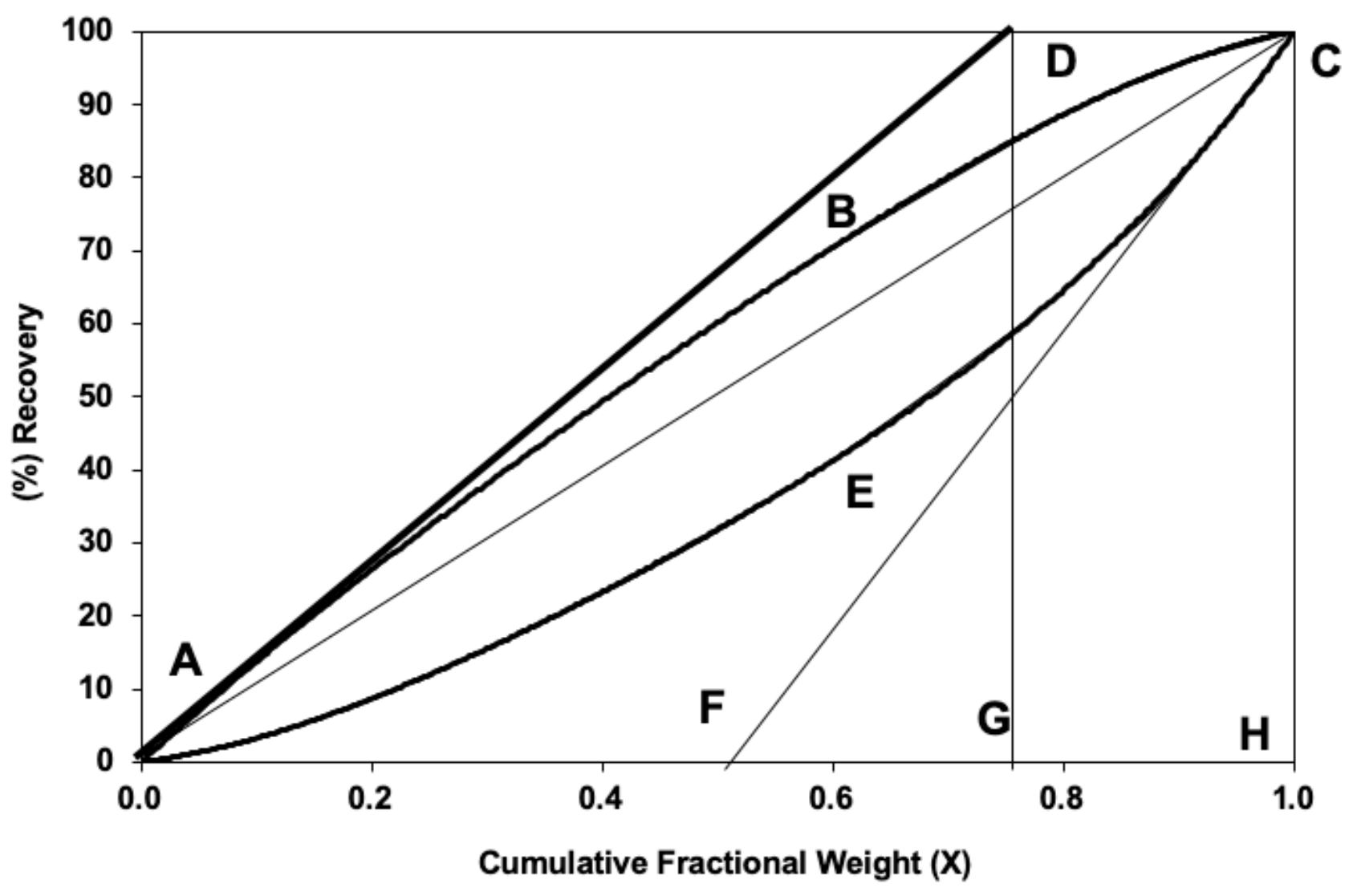

Figure 2

Recovery curves for normal and hypothetical coal crushed to $-75 \mathrm{~mm}$ size 


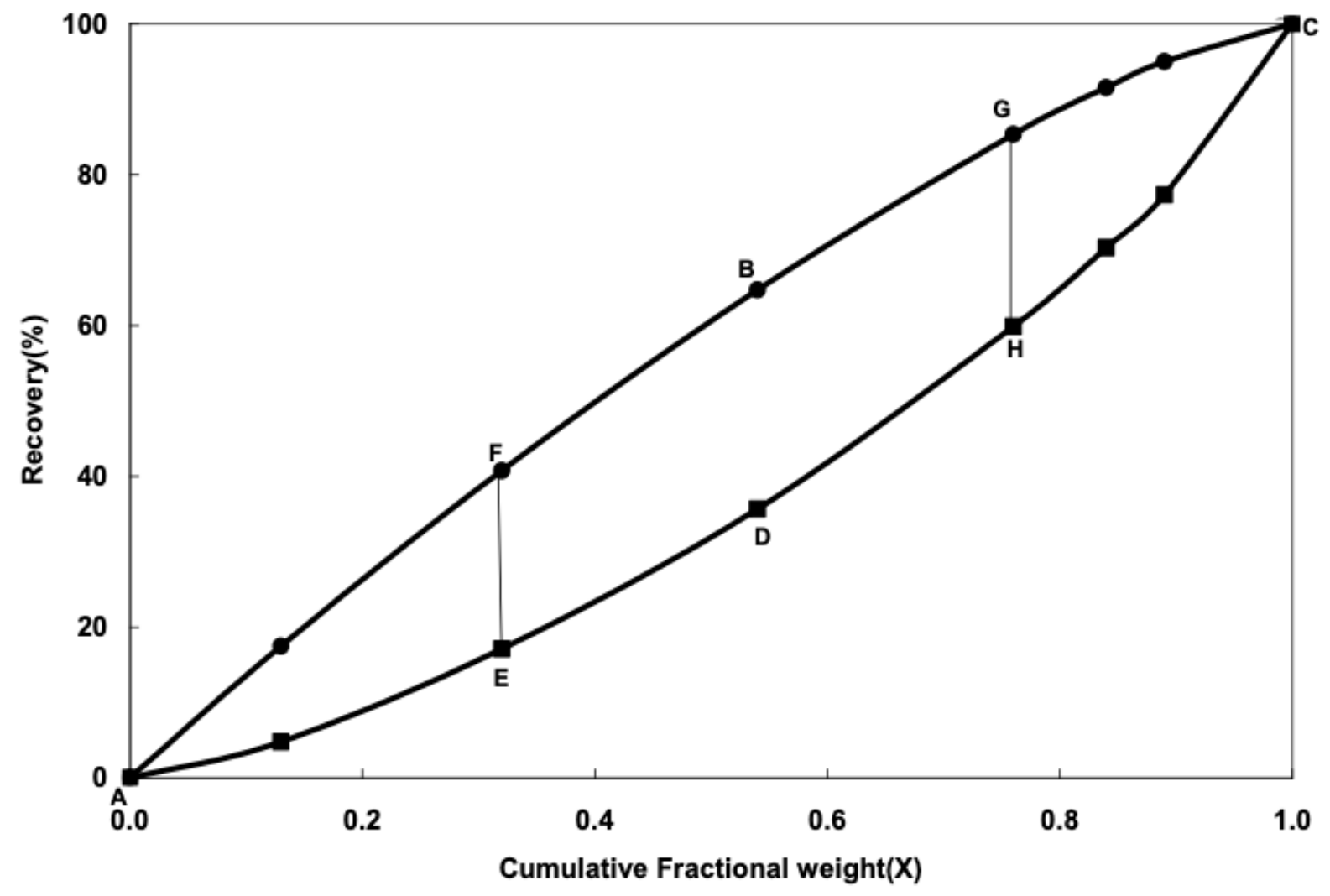

Figure 3

Recovery curves for a given coal at crushed to $-75 \mathrm{~mm}$ size

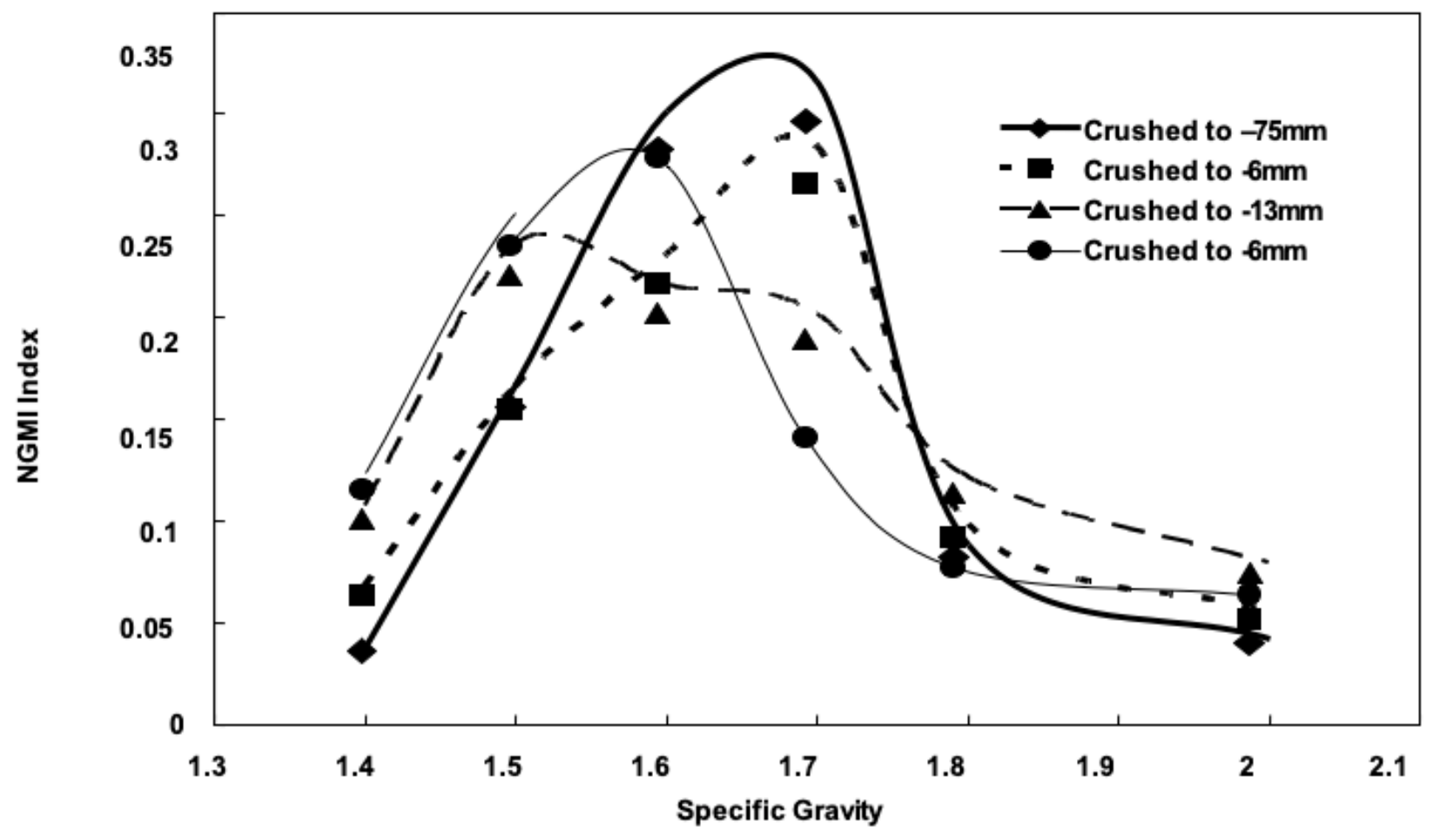


Figure 4

NGMI vs. Specific gravity of separation

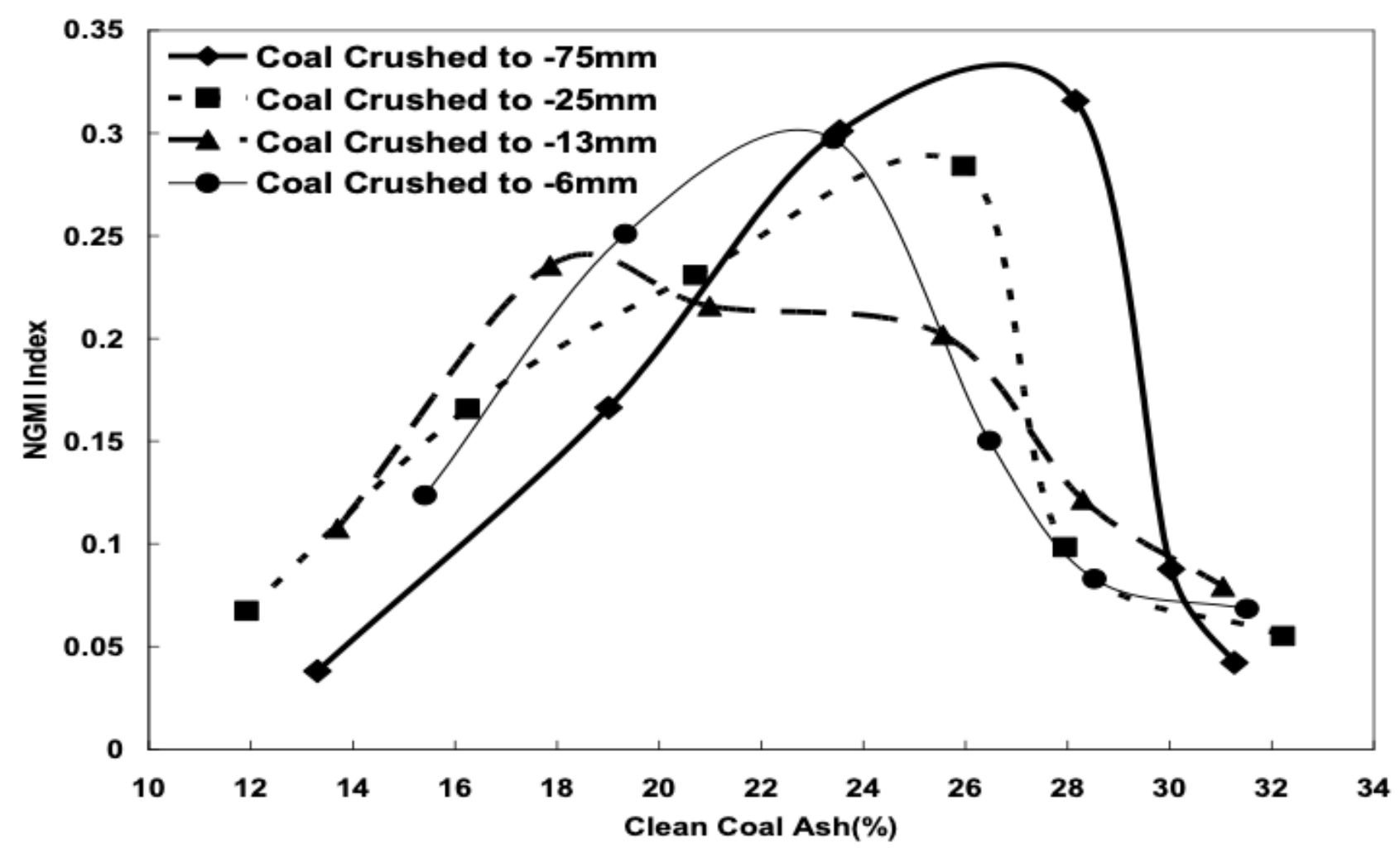

Figure 5

NGMI vs. Clean Coal Ash (\%) 